the Danube is instantaneously transferred to a photon on the other side. Again, the author gives the science a human face: we meet Rupert, possibly a caricature of Zeilinger's postdoc, who is condemned to the tunnels to keep the equipment running. Fortunately, Zeilinger instils him with a sense of humour.

The Vienna group's latest entanglement experiments are performed on a far larger scale - between two of the Canary Islands. A telescope with a one-metre-diameter mirror is used to catch an entangled photon that has travelled 144 kilometres through the turbulent atmosphere. Optimizing the optics, stabilizing the pointing systems and synchronizing the electronics over picoseconds make these experiments challenging, but they have enabled even more careful tests of the counter-intuitive features of quantum entanglement. By using satellites to send the quantum signals, such techniques will one day allow us to distribute entangled information between far-distant locations on Earth.

The book concludes with an outlook of where entanglement will and won't take us. Teleporting humans may be out, as we can't entangle two atom-for-atom clones of a person. But the powerful way in which quantum states carry information opens the path to quantum computing and quantum cryptography. By sharing entanglement over optical fibres (as in the Danube experiment), secret keys can be distributed over short distances. Using entanglement swapping (as in the delayed choice experiment), we might build a quantum repeater - a device for extending key distribution over much longer ranges. Using satellites, secure worldwide communication networks between classical and quantum computers will become possible.

Dance of the Photons is an enjoyable introduction to the strange world of quantum phenomena and the technologies they empower. It gives a foundation from which to ponder the nature of randomness and reality - and whether, in Vienna, the photon dance is performed to a Strauss waltz. Maybe Rupert can tell us over a lager, if he's ever allowed out of the tunnels. .

Geoff Pryde is associate professor of physics at Griffith University, Brisbane, Queensland 4111, Australia.

e-mail:g.pryde@griffith.edu.au

\title{
MATHEMATICS
}

\section{Deception by numbers}

\author{
Jascha Hoffman reads about the rise of nonsense \\ statistics in everything from adverts to voting.
}

$\mathrm{T}$ he statement, published in a newspaper, that only $0.027 \%$ of US felony convictions are wrongful is false. Based on a back-of-the-envelope calculation, it was nevertheless quoted in a court case that ended with a prisoner being sent to his death. Such bad figures are "toxic to democracy", argues science journalist and former mathematics student Charles Seife in his latest book Proofiness, a field guide for spotting the numeric impostors. Seife's polemic against the reporters, politicians, scientists, lawyers and bankers who spread tenacious and specious statistical claims is strident but sobering.

Seife coins the term "proofiness" to refer to the misuse of numbers, deliberate or otherwise. He dubs the simplest quantitative sins "fruit-packing". These include: "cherry-picking" the data, as he says Al Gore did when describing climate change in An Inconvenient Truth; "comparing apples to oranges", as economics pundits do when they neglect to adjust for price inflation; and "apple-polishing", as

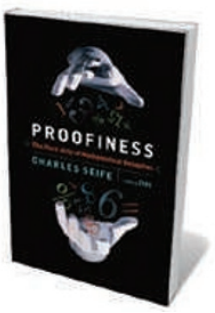

Proofiness: The Dark Arts of

Mathematical

Deception

CHARLES SEIFE

Viking: 2010.

295 pp. $\$ 25.95$ when advertisers use graphics to mislead.

Seife finds bogus figures in every corner of public life - where there are numbers, they will be fudged. He does not spare his fellow hacks, citing the opinion poll as a method for journalists to manufacture their own stories. Surveys, no matter how large their

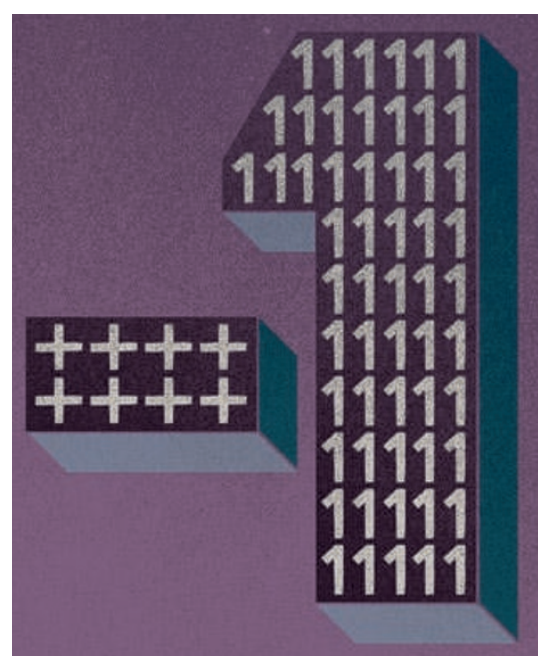

sample sizes and small their margins of random error, may be skewed by slanted questions, biased samples and lying respondents, he explains.

Even the simple act of counting ballots can be fraught with controversy, as in the contested Florida presidential recount in 2000. Claiming the margin of error to have been larger than the 537-vote difference between George W. Bush and Gore in that state, Seife suggests that the race should have been declared too close to call - and therefore, by Florida law, settled by the drawing of lots. He also describes economist Kenneth Arrow's impossibility theorem, which expresses how no voting system can fully capture the preferences of a group.

Seife faults some scientists, too, for overinterpreting their data and making extravagant causal inferences when the evidence is slim. This is particularly problematic in health and nutrition research, he argues,

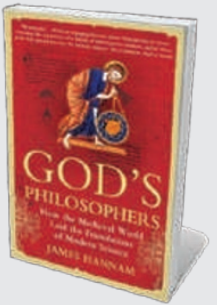

God's Philosophers: How the Medieval World Laid the Foundations of Modern Science James Hannam (Icon Books, 2010; £9.99) Historian James Hannam debunks myths about the European 'dark ages', explaining that medieval people didn't think the world was flat. Rather, the many achievements during the period fed into the later works of Galileo and Newton.

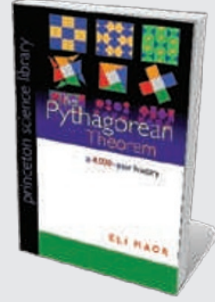

The Pythagorean Theorem: A 4,000-Year History Eli Maor (Princeton Univ. Press, 2010; \$17.95) Pythagoras's famous geometric theorem is central to science. Mathematics historian Eli Maor describes its origins and explains how it features in every scientific field today, pointing out that the formula was known by the Babylonians 1,000 years before Pythagoras. 
casting doubt on studies alleging, for example, that an artificial sweetener causes brain cancer and that debt causes illness. He criticizes a handful of peer-reviewed articles, including some published in Nature, for making claims that, in his eyes, go beyond common sense. For example, Seife thinks it unlikely that wearing red helps Olympic fighters to win, offering his own analysis of results from the 2008 Beijing Olympics as proof. He dismisses other assertions, such as that wide-hipped women give birth to more sons than daughters, as mixing up cause and effect. Seife highlights how scientists can sometimes be seduced by models whose curves fit their data, attributing misguided efforts to find causal relationships to a "misfiring of our pattern-seeking behavior".

Moving on to the legal system, Seife describes how probabilities may be taken out of context in court. Statistics showing that particular crimes or events are rare have wrongly been cited as proof of innocence and guilt - delivering what Seife calls "judicial nonsense". In business, problems arise when numbers are used to under- or overstate potential dangers. Whereas the media tend to overplay risk, Seife reminds us that "underestimating risks, not exaggerating them, is where the money is". He points to prominent company directors who hid their firms' liabilities, and corporate banks that had to be bailed out by governments because of their reckless underestimation of credit risk.

Seife can overstate his case, as when he claims that proofiness is robbing us of "the democratic right to think for ourselves", oiling the "machinery of death" and "crippling our economy". He does little to explain why, given the onslaught of phony figures, many people remain susceptible to them, and he provides few practical suggestions for reducing their influence. Yet there is plenty of healthy scepticism and common sense in Seife's taxonomy of statistical malfeasance. In a world of unreliable numbers, Proofiness is a helpful guide.

Jascha Hoffman is a journalist based in San Francisco, California.

e-mail: jascha@jaschahoffman.com

\section{FORENSICS}

Crime-scene science in the dock

\section{Two books chart the growth of forensic science from its birth to modern times, finds Laura Spinney.}

$\mathrm{H}$ ere are two books that span an era. Douglas Starr's The Killer of Little Shepherds describes the birth of modern forensic science in France in the late nineteenth century, revealing how it led to the capture of a serial killer. Michael Capuzzo's The Murder Room revisits cold cases from the past 50 years, just as the field of forensics is beginning to modernize and move in a new direction. Both accounts are riveting. But whereas Starr knows he is writing about a period of intellectual upheaval, Capuzzo seems impervious to the winds of change.

Starr's hero is the French physician and criminologist Alexandre Lacassagne, who established the ground rules for many forensic disciplines, from autopsy and bloodspatter analysis to toxicology and psychology. He worked in exciting times for the field. Between 1885 and the First World War, when Lacassagne's school of forensics in Lyons was influential, anthropologists Francis Galton in Britain and Juan Vucetich in Argentina were classifying fingerprint types for identification purposes, Austrian physician Karl Landsteiner discovered blood groups and, in 1897, a Parisian blaze provided the backdrop for the first identification of corpses by their teeth. The application of probability theory to the interpretation of forensic evidence in court was highlighted by the Dreyfus affair the trial in France of artillery officer Alfred Dreyfus for treason, which hinged on the analysis of handwriting in an incriminating document.

Lacassagne brought such forensic advances to bear on the case of Joseph Vacher, a serial murderer whose
The Killer of Little Shepherds: A True Crime Story and the Birth of Forensic Science DOUGLAS STARR

Knopf/Simon \& Schuster: 2010/2011. 320 pp. $\$ 26.95 / £ 16.99$

The Murder Room: The Heirs of Sherlock Holmes Gather to Solve the World's Most Perplexing Cold Cases

MICHAEL CAPUZZO

Gotham/Michael Joseph: 2010. 448 pp/384 pp. $\$ 26 / £ 17.99$

victims included young shepherd boys out watching their flocks in rural France. Through analyses of the crime scenes and victims' bodies, the criminologist showed that Vacher's crimes were premeditated and systematic, implying that the killer was not insane. Vacher was convicted in 1898, and executed by guillotine.

Similar forensic methods are still used more than a century later. Capuzzo's heroes in The Murder Room are William Fleisher, a former special agent with the US Federal Bureau of Investigation, and forensic psychologist Richard Walter and forensic sculptor Frank Bender, who together founded the Vidocq Society in Philadelphia, Pennsylvania, in 1990. Taking its name from the nineteenth-century French crook-turned-crimefighter Eugène Vidocq, the non-profit, closed society brings together 150 volunteer experts to solve crimes that have gone cold. From forensic scientists to business leaders, the membership pools its knowledge once a month, over lunch, to home in on perpetrators

\section{DNATURE.COM}

For a special issue focusing on science in court, see: go.nature.com/eZ6Pwk

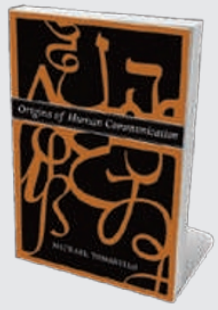

Origins of Human Communication Michael Tomasello (MIT Press, 2010; £13.95) Developmental psychologist Michael Tomasello examines the evolutionary origins of human communication. Sharing information with and helping others, he suggests, is the main purpose of speech and gesture. Such goals require the development of complex linguistic grammars.

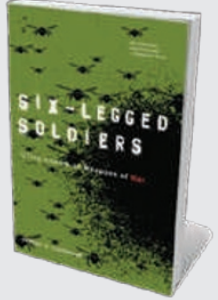

Six-Legged Soldiers: Using Insects as Weapons of War Jeffrey A. Lockwood (Oxford Univ. Press, 2010; £9.99) From scorpions used by Roman armies to beetle infestations spread in the cold war, entomologist Jeffrey Lockwood reveals insects' military uses. Reviewer Kenneth J. Linthicum described it as "an excellent account" (Nature 456, 36-37; 2008). 